\title{
Synthesis and Characterization of Polymers from Bisphenol Derivatives and Perfluorinated Aromatic Compounds
}

\author{
By Kiyoshi ENDO* and Takashi YAMADE
}

Polycondensation of 2,2-bis(4-hydroxyphenyl)hexafluoropropane (BAF) or bisphenol-A (BPA) with perfluorobiphenyl (PFBP) or hexafluorobenzene (HFB) was investigated. The polycondensation of BAF with PFBP in the presence of NaH in $N, N$-Dimethylacetamide proceeded easily to give high molecular weight polymers. The polycondensation of $\mathrm{HFB}$ with $\mathrm{BAF}$ also took place, but the polymer yield and the $M_{\mathrm{n}}$ of the obtained polymer were lower than that of BAF with PFBP. When the polycondensation of 2,2-bis(4-propylcarbamoylphenyl)hexafluoropropane (PCBAF) as a BAF derivative with PFBP was carried out, a highest rate of polymerization was observed. The ${ }^{19} \mathrm{~F}$ NMR spectra of the resulting polymer indicate that the structure with respect to the perfluorinated aromatic compound in the chain consists predominantly of para-position linkage unit. All the polymers obtained showed a high thermal stability and high contact angles of water.

KEY WORDS: Polycondensation / 2,2-Bis(4-hydroxyphenyl)hexafluoropropane / Perfluorobiphenyl / Hexafluorobenzene / Thermal

Stable Polymer / Contact Angles /

Polymer contains fluorine atom in the chain shows various excellent properties such as thermal stability, chemical resistance, low dielectric constant, and low hygroscopicity. Namely, the fluorine-containing polymers are of great interest as functional materials. Typical fluorine-containing polymer is poly(tetrafluoroethylene) (PTFE). The copolymers with fluorinated vinyl monomers containing ether bond have been synthesized to change the properties of PTFE. ${ }^{1-4}$ In addition, fluorine-containing polyethers bearing ether bond in the main chain show good physical and thermal properties. ${ }^{5-9}$

In a polymer synthesis, aromatic ring introduced in the main chain is a simple method for synthesizing thermal stable polymers. Taking a symmetry of polymers into consideration, an introduction of substituents at the para-position is prefarable. ${ }^{10-13}$ The polycondensation reaction of atomatic dihalide and bisphenol or aromatic diamine using a nucleophilic substitution reaction is an important method for synthesizing thermal stable polymers. Moreover, the polycondensation using fluorinated aromatic compounds as monomers can give the polymer having not only thermal stability but also the unique character. Adhesives property of fluorine-containing polymer is inferior as compared with other materials due to low surface energy. This disadvantage may be improved by introduction of aromatic ring in the polymer main chain.

Many studies on thermally stable fluorine-containing polymers synthesized by a polycondensation method have been reported. ${ }^{14-20}$ However, there are few reports on detailed study of the polycondensation of perfluorinated aromatic compounds such as perfluorobiphenyl (PFB) with 2,2-bis(4-hydroxyphenyl) hexafluoropropane (BAF), although a synthesis of the polymers consisting of $\mathrm{PFB}$ and $\mathrm{BAF}$ has been reported biefly. ${ }^{21}$ Moreover, the polymer containing triphenyl methane and tetraphenyl methane was synthesized using isocynate- masked bisphenols. ${ }^{22}$ If the polycondensation of these compounds undergoes as shown in Scheme 1, it will be expected to give polymers with thermal resistance and water repellency.

In this article, the polycondensation of 2,2-bis(4-hydroxyphenyl)hexafluoropropane (BAF) or 2,2-bis(4-propylcarbamoylphenyl)hexafluoropropane (PCBAF) which is the isocynate-masked monomer of BAF with perfluorobiphenyl (PFBP) or hexafluorobenzene (HFB) was investigated. The structure of the polymers, and thermal stability and film property of the resulting polymers were also examined.

\section{EXPERIMENTAL}

\section{Materials}

PFB, HFB, BAF, BA, dimethylsulfoxide (DMSO), NaH, and $N, N$-dimethylacetamide (DMAc) purchased from Wako Co. Inc. were used as received. PCBAF was synthesized according to a similar reported method ${ }^{21,22}$ in the following; a solution of BAF $(0.03 \mathrm{~mol}), n$-propylisocyanate $(15 \mathrm{~mL})$, and triethylamine $(2 \mathrm{~mL})$ in $300 \mathrm{~mL}$ of toluene was heated at $110^{\circ} \mathrm{C}$ for $10 \mathrm{~h}$. The reaction products were evaporated to dryness giving a crude product. Crystallization twice from $\mathrm{CH}_{2} \mathrm{Cl}_{2}$ to hexane gave pure PCBAF in $96 \%$ yield; ${ }^{1} \mathrm{H}$ NMR $\left(\mathrm{CDCL}_{3}\right): \delta 0.98\left(\mathrm{t}, 6 \mathrm{H}, J=7.4,-\mathrm{CH}_{2} \mathrm{CH}_{2} \mathrm{CH}_{3}\right), 1.56-1.65(\mathrm{~m}$, $\left.4 \mathrm{H},-\mathrm{CH}_{2} \mathrm{CH}_{2} \mathrm{CH}_{3}\right), 3.22-3.27\left(\mathrm{~m}, 4 \mathrm{H},-\mathrm{CH}_{2} \mathrm{CH}_{2} \mathrm{CH}_{3}\right), 5.08(\mathrm{t}$, $J=5.8,2 \mathrm{H}, \mathrm{NH}), 7.15(\mathrm{~d}, J=8.8,4 \mathrm{H}, \mathrm{ArH}), 7.37$ (d, $J=8.4$, $4 \mathrm{H}, \mathrm{ArH})$. Other reagents were used after purification by conventional methods.

\section{Polymerization Procedure}

To a solution of perfluorinated aromatic compound (1.6 mmol) and the BA derivative $(1.6 \mathrm{mmol})$ in $10 \mathrm{~mL}$ of solvents was added sodium hydride $(4 \mathrm{mmol})$ at $0^{\circ} \mathrm{C}$ under a nitrogen

Department of Applied Chemistry \& Bioengineering, Graduate School of Engineering, Osaka City University, Sugimoto, Sumiyoshi-ku, Osaka 558-8585, Japan

*To whom correspondence should be addressed (Tel: +81-6-6605-2697, Fax: +81-6-6605-2697, E-mail: endo@a-chem.eng.osaka-cu.ac.jp). 
$\mathrm{F}-\mathrm{Ar}-\mathrm{F}+\mathrm{RO} \longrightarrow \mathrm{OR}$
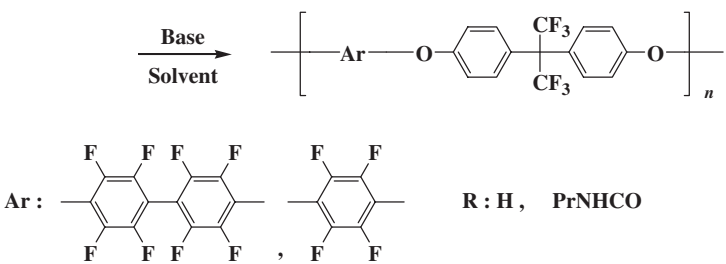

$\mathrm{R}: \mathrm{H}, \quad$ PrNHCO
II

Scheme 1. Polycondensation of perfluorinated aromatic compounds with BAF derivatives.

atmosphere. The mixture was then allowed to warm up to the reaction temperature. After the polymerization, the products were poured into $200 \mathrm{~mL}$ of $3 \%$ hydrochloric acid to precipitate the polymer formed. Isolated polymer was purified by precipitation from $\mathrm{THF} /$ methanol/3\% hydrochloric acid and dried in vacuo at room temperature for $24 \mathrm{~h}$. Polymer yields were determined by gravimetric method.

\section{Characterization of Polymers}

The structure of monomer was analyzed by ${ }^{1} \mathrm{H} \mathrm{NMR}$ spectroscopy using a JEOL A-400 spectrometer in $\mathrm{CDCl}_{3}$ with TMS as an internal standard. The number-average molecular weight $\left(M_{\mathrm{n}}\right)$, the weight-average molecular weight $\left(M_{\mathrm{W}}\right)$, and the polydispersity index $\left(M_{\mathrm{w}} / M_{\mathrm{n}}\right)$ of the polymers were determined by gel permeation chromatography (GPC) using a Tosoh 8000 series system in tetrahydrofuran (THF) at a flow rate of $1 \mathrm{~mL} / \mathrm{min}$ at $38^{\circ} \mathrm{C}$. Standard polystyrenes purchased from Tosoh Co. Ltd. were used for molecular weight calibration. The structure of polymer was mainly analyzed by ${ }^{19} \mathrm{~F}$ NMR spectroscopy measured in $\mathrm{CDCl}_{3}$ with $\mathrm{CFCl}_{3}$ as an internal standard. Thermal analysis was performed by thermo gravimetry (TG) using a SEIKO TG/DTA 6200 in nitrogen atmosphere at a heating rate of $10^{\circ} \mathrm{C} / \mathrm{min}$ in the range from 25 to $500^{\circ} \mathrm{C}$, and by differential scanning calorimetry (DSC) using a SEIKO DSC 6200 in nitrogen atmosphere at a heating rate of $20^{\circ} \mathrm{C} / \mathrm{min}$ in the range from 25 to $250{ }^{\circ} \mathrm{C}$.

\section{Preparation of Polymer Film}

The film of polymer was produced by casting method. The polymer $(20 \mathrm{mg})$ was dissolved in $4 \mathrm{~mL}$ of $o$-dichlorobenzene, and the film was formed on PTFE plate. The transparent film of polymer was obtained by heating at $120^{\circ} \mathrm{C}$.

\section{RESULTS AND DISCUSSION}

\section{Polycondensation of PFB with BAF}

Polycondensation of BAF and PFB in the presence of bases as a catalyst in various solvents was carried out, and the results are listed in Table I. Such polycondensation reaction is usually carried out at above $100^{\circ} \mathrm{C}^{20,22}$ When such reaction was carried out at elevated temperature, ether exchange reaction may be operated. To avoid such reaction, we examined the
Table I. Polycondensation of perfluorobiphenyl with bisphenol-AF at $30^{\circ} \mathrm{C}$ for $24 \mathrm{~h}$

\begin{tabular}{cccccc}
\hline Run No. & Base & Solvent $^{\mathrm{a}}$ & $\begin{array}{c}\text { Polymer } \\
\text { Yield (\%) }\end{array}$ & $M_{\mathrm{n}} \times 10^{-4}$ & $M_{\mathrm{w}} / M_{\mathrm{n}}$ \\
\hline 1 & $\mathrm{NaH}$ & DMAc & 96 & 8.2 & 2.8 \\
2 & $\mathrm{NaH}$ & DMSO & 74 & 0.4 & 1.3 \\
3 & $\mathrm{KOH}$ & DMAc & 95 & 2.1 & 1.4 \\
4 & $\mathrm{KOH}$ & DMSO & 69 & 0.6 & 1.1 \\
5 & $\mathrm{~K}_{2} \mathrm{CO}_{3}$ & DMAc & 93 & 4.4 & 1.9 \\
6 & $\mathrm{~K}_{2} \mathrm{CO}_{3}$ & DMSO & 87 & 2.2 & 1.5 \\
\hline
\end{tabular}

a: DMAc: $N, N$-Dimethylacetamide. b: Methanol insoluble part.

polycondensation of $\mathrm{BAF}$ and $\mathrm{PFB}$ at $30^{\circ} \mathrm{C}$. The polycondensation took place easily in the presence of all bases examined, and a high molecular weight polymer was obtained in the presence of $\mathrm{NaH}$ as a base in a good yield. The same reaction was reported in a previous paper, but the reaction was carried out in the presence of $\mathrm{K}_{2} \mathrm{CO}_{3}$ to give low yield even though the reaction time was long. ${ }^{21}$ Thus, the presence of $\mathrm{NaH}$ was important factor to promote the condensation reaction. When DMAc was used as the polymerization solvent, a high molecular weight polymer was obtained in comparison to DMSO. Namely, the polymerization solvent is also an important factor to produce high molecular weight polymers in the polycondensation of BAF and PFB.

Since a high molecular weight polymer in a high yield was obtained in DMAc solvent, the polycondensation in the presence of $\mathrm{NaH}$ in DMAc was examined in detail. The kinetic curves are shown in Figure 1, in which the results for the reaction of PCBAF and PFB in the presence of $\mathrm{NaH}$ in DMAc are also indicated to comparison. The polymer yield increased with reaction time. Relationships between the polymer yield and $M_{\mathrm{n}}$ of the polymer are shown in Figure 2, and the relation showed a typical polycondensation reaction, i.e., the $M_{\mathrm{n}}$ of the polymer increased remarkably as the polymerization progressed. The effect of polymerization temperature on the polycondensation was observed, and the polycondensation rate at $150{ }^{\circ} \mathrm{C}$ was higher than that at $30^{\circ} \mathrm{C}$.

In a previous paper, carbamates bisphenol could be rapid cleaved by a base to generate the phenoxide to form high

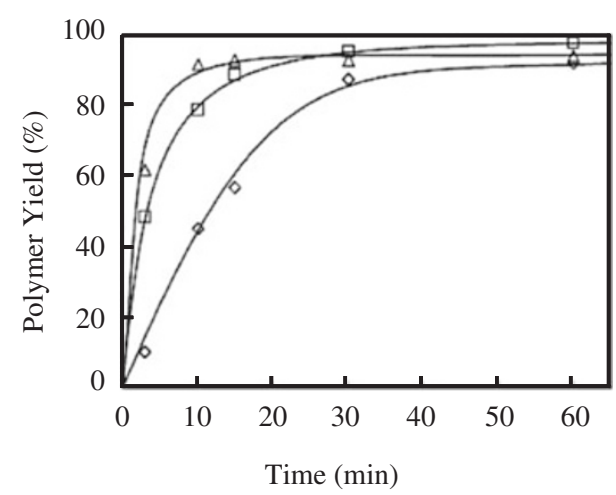

Figure 1. Polycondensation of PFB with $(\diamond) \mathrm{BAF}$ polymerized at $30^{\circ} \mathrm{C},(\square)$ $\mathrm{BAF}$ polymerized at $150^{\circ} \mathrm{C}$, and $(\triangle)$ PCBAF polymerized at $150^{\circ} \mathrm{C}$ in the presence of $\mathrm{NaH}$ in DMAc. 


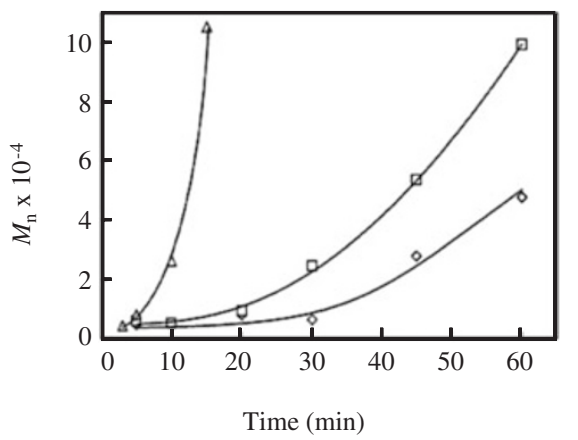

Figure 2. Relationship between Time and $M_{\mathrm{n}}$ of polymers for the polycondensation of PFB with $(\diamond) \mathrm{BAF}$ polymerized at $30^{\circ} \mathrm{C},(\square) \mathrm{BAF}$ polymerized at $150^{\circ} \mathrm{C}$, and $(\triangle)$ PCBAF polymerized at $150^{\circ} \mathrm{C}$ in the presence of $\mathrm{NaH}$ in DMAc.

molecular weight polymer. ${ }^{23,24}$ PCBAF, which the hydroxyl group of BAF is masked by propylcarbamoyl group, was used for the polycondensation instead of BAF. As a result, the rate of polymerization BAF and PCBAF was the highest and gave a transparent material. The ${ }^{1} \mathrm{H}$ NMR spectrum of the polymer obtained from BAF and PCBAF showed peaks at 7.05 and $7.41 \mathrm{ppm}$, which assigned to be the phenyl moiety, but the $n$-propylcalbamoyl groups appeared at 0.98, 1.56-1.65, $3.22-3.27$, and $5.08 \mathrm{ppm}$ in the PCBAF were not observed completely in the polymer. Namely, the polymer obtained from polycondesation of PFB and PCBAF is the same spectrum to that obtained from the polycondensation of $\mathrm{PFB}$ and $\mathrm{BAF}$, indicating that the polymerization of $\mathrm{PFB}$ and $\mathrm{PCBAF}$ gave the same structure to that obtained from PFB and BAF as shown in Scheme 1 .

\section{Polycondensation of HFB with BAF}

Polycondensation of BAF and HFB in the presence of $\mathrm{NaH}$ in DMAc at $30^{\circ} \mathrm{C}$ was examined. Relationships between reaction time and polymer yield or $M_{\mathrm{n}}$ are shown in Figure 3. The polymer yield and the $M_{\mathrm{n}}$ of the polymer increased as a function of reaction time. However, the rate of polycondensation of BAF and HFB was extremely slow as compared to the polymerization with PFB. This may be explained by a decrease of electron-withdrawing ability due to the presence of perfluorinated aromatic moiety, leading to decrease the rate of a nucleophilic substitution reaction. The $M_{\mathrm{n}}$ of the polymer was also lower than that obtained from PFB.

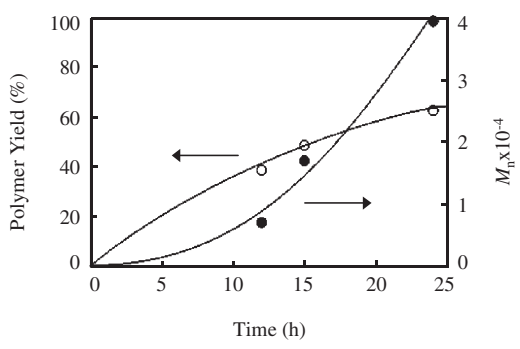

Figure 3. Polycondensation of BAF with HFB.

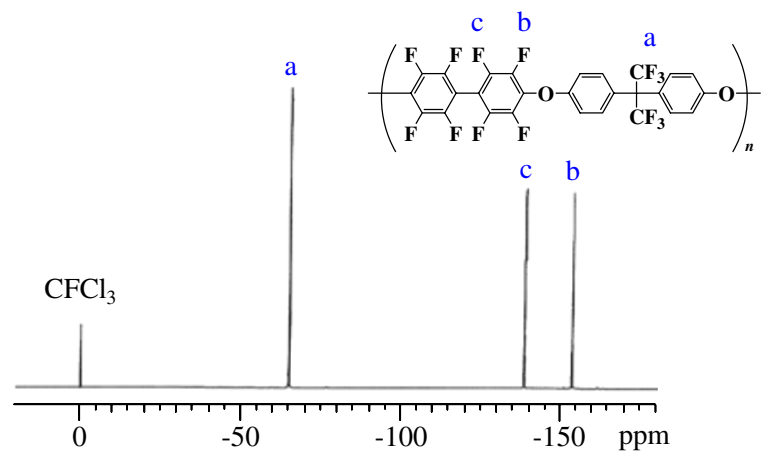

Figure 4. ${ }^{19} \mathrm{~F}$ NMR spectrum of the polymer obtained from polycondensation of BAF with PFB.

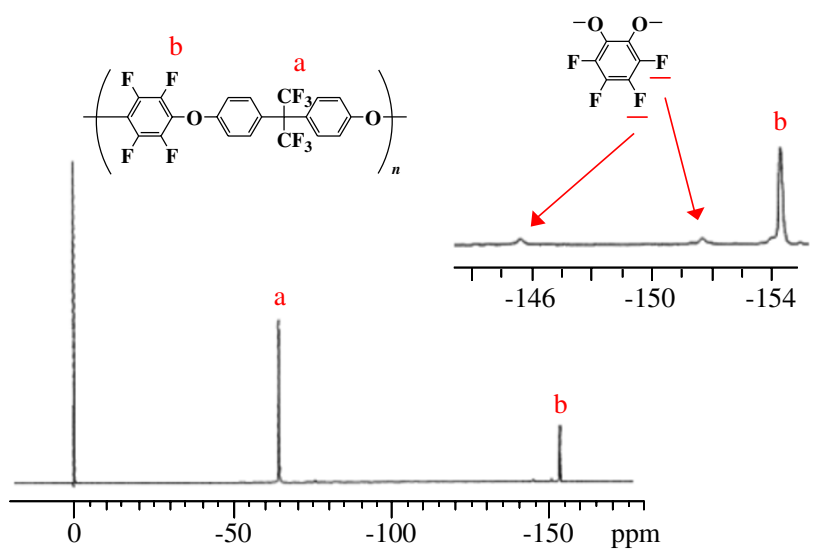

Figure 5. ${ }^{19} \mathrm{~F}$ NMR spectrum of the polymer obtained from polycondensation of BAF with HFB.

\section{Analysis of Polymer Structures}

The structure of polymers was checked by ${ }^{19} \mathrm{~F}-\mathrm{NMR}$ spectroscopy. Figure 4 shows the ${ }^{19}$ F-NMR spectrum of the polymer obtained from the polycondensation of PFB with BAF. A peak appeared at $-65 \mathrm{ppm}$ based on trifluoromethyl group, and the peaks based on PFB unit were observed at $-138 \mathrm{ppm}$ and $-153 \mathrm{ppm}$ as assigned on the figure. The polymer obtained from PFB and PCBAF also gave the same ${ }^{19} \mathrm{~F}-\mathrm{NMR}$ spectrum. This demonstrated that the polymer consists of the predominant para-positon linkage structure without structural defects such as branching and cross-linking. On the other hand, the polymer obtained from the polycondensation of BAF with HFB is shown in Figure 5. Peaks appeared at $-65 \mathrm{ppm}$ and $-154 \mathrm{ppm}$ base on $\mathrm{HFB}$ unit substituted at para-position. In addition, two very small peaks also appeared at $-146 \mathrm{ppm}$ and $-152 \mathrm{ppm}$ derived from ortho-position of HFB, indicating that the contents of the 1,2linkage of HFB unit are very small. Thus, we concluded that the synthesized polymers have a repeating structure as shown in Figure 6.

\section{Thermal Properties of Polymers}

The structures of the polymers examined are shown in Figure 6, and each repeating unit of the polymer was 


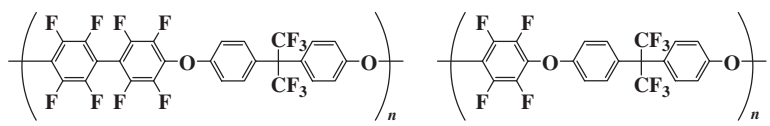

Polymer I

Polymer II

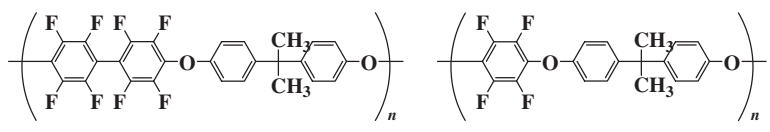

Polymer III

Polymer IV

Figure 6. The structures of polymer obtained from perfluorinated aromatic compounds with bisphenol derivatives.

Table II. Thermal stability of polymer I to IV

\begin{tabular}{lccccc}
\hline Polymer & $M_{\mathrm{n}} \times 10^{-4}$ & $T_{\mathrm{d} 5 \%}\left({ }^{\circ} \mathrm{C}\right)^{\mathrm{a}}$ & $T_{\mathrm{d} 10 \%}\left({ }^{\circ} \mathrm{C}\right)^{\mathrm{b}}$ & $W_{800}(\%)^{\mathrm{c}}$ & $T_{\mathrm{g}}\left({ }^{\circ} \mathrm{C}\right)$ \\
\hline I & 8.0 & 517 & 530 & 44 & 183 \\
II & 1.3 & 497 & 512 & 54 & 178 \\
III & 7.6 & 504 & 510 & 45 & 164 \\
IV & 0.9 & 485 & 493 & 47 & 142 \\
\hline
\end{tabular}

a: Temperature for $5 \%$ weight loss under a nitrogen atmosphere. b: Temperature for $10 \%$ weight loss under a nitrogen atmosphere. c: Weight loss determined from TGA curve at $800^{\circ} \mathrm{C}$.

abbreviated as polymer I to polymer IV. The thermal stability was checked by TGA and DSC measurements, and the results are listed in Table II. All the polymers obtained in this study did not decompose up to about $400{ }^{\circ} \mathrm{C}$, and temperature for $5 \%$ weight loss $\left(T_{\mathrm{d} 5 \%}\right)$ of the polymer was also high $\left(>480{ }^{\circ} \mathrm{C}\right)$. Although a clear relation between $T_{\mathrm{d} 5 \%}$ or $T_{\mathrm{d} 10 \%}$ and the structure of the polymers, the thermal stability of the polymer decreased with decreasing the fluorine contents in the polymers. The thermal decomposition behavior of polymers consisting of same bisphenol derivatives was similar at the early stage of decomposition, suggesting that the weight loss of the polymer initiates at bisphenol moiety in the main chain. On the other hand, $T_{\mathrm{g}}$ decreased as a ratio of fluorine and aromatic rings in monomer sequence, but all the polymers showed a high $T_{\mathrm{g}}$.

\section{Properties of Polymer Films}

The solubility of polymer I to IV was examined, and the results are shown in Table III. All polymers of I to IV are soluble in many organic solvents such as acetone, chloroform,

Table III. Solubility of polymer I to IV for various organic solvents ${ }^{\mathrm{a}}$

\begin{tabular}{lcccc}
\hline \multicolumn{1}{c}{ Solvent } & Polymer I & Polymer II & Polymer III & Polymer IV \\
\hline Methanol & - & - & - & - \\
Cyclohexane & - & - & - & - \\
DMF & + & + & + & + \\
THF & + & + & + & + \\
Acetone & + & + & + & + \\
Diethylether & + & + & - & - \\
Acetonitrile & - & +- & - & +- \\
Chloroform & + & + & + & + \\
\hline
\end{tabular}

a: +: Soluble, -: Insoluble, +-: Swelling.

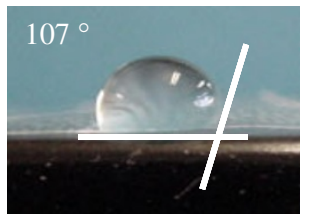

Polymer I

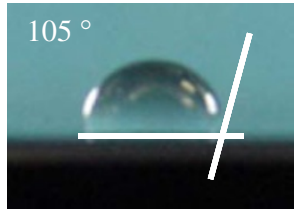

Polymer III

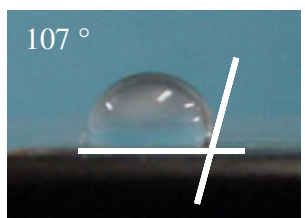

Polymer II

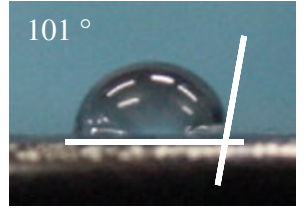

Polymer IV
Figure 7. Contact angles of polymer I to IV.

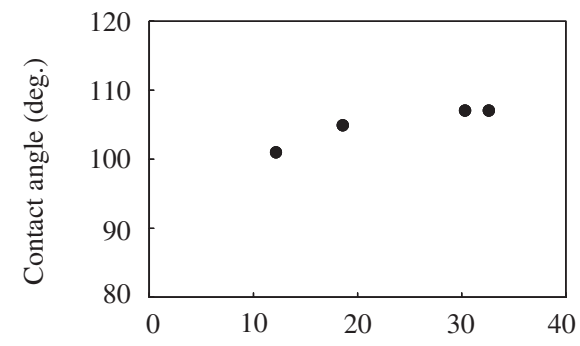

Fluorine content in the repeating unit $(\%)$

Figure 8. Relationship between fluorine content in the repeating unit and contact angle of polymer I to IV.

DMF and THF, and gave a transparent and flexible film by casting from $o$-dichlorobenzene solution. To check the water repellency of the films, contact angles of water were measured. The results of the measurement are shown in Figure 7. The data obtained from Figure 7, the contact angles of these polymers was determined as shown in Figure 8, form which the contact angles increased with increase of the fluorine content in the monomer sequence.

The film of polymer I was treated with the acid and the alkali to examine acid and alkali resistant. Even after treatment with concentrated hydrochloric acid and $30 \% \mathrm{NaOH}$ aqueous for $24 \mathrm{~h}$, the changes of the molecular weight and degradation of the film were not observed. Thus, it is clear that polymer I film has high acid and alkali resistance.

\section{CONCLUSION}

The polycondensation of PFB with BAF using $\mathrm{NaH}$ as base in DMAc gave high molecular weight polymers. Although the polycondensation of HFB with BAF also took place, polymer yield and the $M_{\mathrm{n}}$ of the obtained polymer were low in comparison to the polycondensation of PFB and BAF. Moreover, when the masked BAF, i.e., PCBAF was used, a high molecular weight polymer was synthesized. The ${ }^{19} \mathrm{~F}$ NMR spectrum of polymer indicates the structure of polymer consists of predominant para-position linkage structure with respect to 
perfluorinated aromatic compound. The polymer I to IV have a high decomposition temperature, $T_{\mathrm{g}}$ and high contact angles to water.

\section{REFERENCES}

1. S. Yamaguchi, Kobunshi Ronbunshu, 48, 821 (1991).

2. E. Tsuchida, K. Yamamoto, E. Shouji, and J. Katou, Macromolecules, 27, 7504 (1994).

3. J. Runt, L. Jin, and S. Talibuddin, Macromolecules, 28, 2781 (1995).

4. T. J. Romack and J. M. DeSimone, Macromolecules, 28, 8429 (1995).

5. D. Sianesi, A. Pasetti, and C. Corti, Makromol. Chem., 86, 308 (1965).

6. D. F. Persico, G. E. Gerhardt, and R. J. Lagow, Makromol. Chem., Rapid Commum., 6, 85 (1985)

7. D. F. Persico, G. E. Gerhardt, and R. J. Lagow, J. Am. Chem. Soc., 107, 1197 (1985).

8. J. Pacansky, M. Miller, W. Hatton, B. Liu, and A. Scheiner, J. Am. Chem. Soc., 113, 329 (1991).

9. W. C. Bunyard, T. J. Romack, and J. M. DeSimone, Macromolecules, 32, 8224 (1999).

10. M. T. Bishop, F. E. Karasz, P. S. Russo, and K. H. Langley,
Macromolecules, 18, 86 (1985).

11. N. Shibuya and R. S. Porter, Macromolecules, 25, 6495 (1992).

12. Y. Z. Meng, S. C. Tjong, A. S. Hay, and S. J. Wang, J. Polym. Sci., Part A: Polym. Chem., 39, 3218 (2001).

13. A. S. Al-Hussaini, M. Klapper, T. Pakula, and K. Müllen, Macromolecules, 37, 8269 (2004).

14. G. L. Tullos, P. E. Cassidy, and A. K. St. Clair, Macromolecules, 24, 6059 (1991).

15. Y. Saegusa, A. Kojima, and S. Nakamura, Makromol. Chem., 194, 777 (1993).

16. Y. Saegusa, M. Horikiri, D. Sakai, and S. Nakamura, J. Polym. Sci., Part A: Polym. Chem., 36, 429 (1998).

17. Y. Saegusa and T. Sakai, J. Polym. Sci., Part A: Polym. Chem., 38, 1873 (2000).

18. C. Yang, H. Chiang, and Y. Su, Polym. J., 36, 979 (2004).

19. Y. Watanabe, Y. Shibasaki, S. Ando, and M. Ueda, Polym. J., 38, 79 (2006).

20. S. Xiao, J. Y. Wang, K. Jin, X. Jian, and Q. Peng, Polymer, 44, 7369 (2003).

21. J. A. Irvin, C. I. Neef, K. M. Kane, P. E. Cassidy, G. Tullos, and A. K. St. Clair, J. Polym. Sci., Part A: Polym. Chem., 30, 1675 (1992).

22. K. Miyatake, K. Oyaizu, E. Tsuchida, and A. S. Hay, Macromolecules, 34, 2065 (2001).

23. L. Wang, Y. Z. Meng, S. J. Wang, X. Y. Shang, L. Li, and A. S. Hay, Macromolecules, 37, 3151 (2004).

24. L. Wang, H. N. Carvalho, and A. S. Hay, J. Chem. Soc., Chem. Commun., 1221 (1991) 